\title{
A One Year Forecasting Project For Publicly Traded Companies
}

Fred Petro, Pepperdine University, USA

\begin{abstract}
This project is intended to teach students to apply the material covered in their first graduate accounting course. This is accomplished by applying the material to an actual company selected by each team. The project is described as follows: The project includes a computerized spreadsheet preparation of a master budget forecast for an actual publicly traded company for one year into the future. . The dates depend upon when the annual reports are prepared for your company. The forecast begins the day following the last available published annual report. The forecast does not comprise any actual numbers regardless of when the actual annual or quarterly statements are prepared for the company selected. The actual balance sheet, income statement and statement of cash flow from the preceding year are included with the forecasted balance sheet, income statement and statement of cash flow. The company must have a physical inventory, and accounts receivable from sales. The company may not be one in which any team member(s) are employed. The forecast will include the following items:

1. Introduction, including the history of the company and a description of the company plan and policies as given in the project

2. Sales budget (twelve months).

3. Schedule of purchases (twelve months).

4. Schedule of collection of credit sales (accounts receivable) and cash sales (twelve months).

5. Cash budget (twelve months).

6. An Income statement (for the current year and the projected year).

7. A Balance sheet (for the current year and the projected year).

8. A Statement of cash flow (for the current year and the projected year).

9. Cost-profit-volume analysis (twelve months).

10. Conclusion and recommendations
\end{abstract}

\section{PROJECT INSTRUCTIONS}

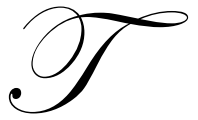

he projects will be done in teams on the same company selected by the team with the approval of the professor. The number of team members will depend on the number of people in the class. Each person on the team will be responsible for preparing, submitting work by email and presenting a section of the master budget. If a team member drops the course, the remaining team members have the responsibility of revising the team member responsibilities exactly in accordance with the syllabus for the number of team members remaining. Accordingly, each team member will be responsible for preparing, submitting work by email and presenting the entire project in accordance with the revised assignment of responsibilities.

Teams are required to be made up as follows:

For a team of three: one person will prepare and present (items 1-4) the introduction, a twelve month sales budget, a twelve month schedule of purchases and schedule of the collection of sales for twelve months ; one person will prepare and present (items 5,7 \& 8) a twelve month cash budget, a statement of cash flow for the current and projected year and a balance sheet for the current year and for the projected year; one person will prepare and present (items 6, 9 \& 10) an income statement for the current and projected year, a twelve month cost-volumeprofit analysis including a chart depicting the projection together with at least three other scenarios that also include charts. This person will also prepare and present the conclusion and recommendations. 
For a team of two: one person will prepare and present (items $1-5 \& 8$ ) the introduction, a twelve month sales budget, a twelve month schedule of purchases and schedule of the collection of sales for twelve months, a twelve month cash budget and a statement of cash flow for the current and projected year; one person will prepare and present (items $6,7,9 \& 10$ ) a balance sheet for the current year and for the projected year, an income statement for the current year and for the projected year and a twelve month cost-volume-profit analysis including a chart depicting the projection together with at least three other scenarios that also include charts. This person will also prepare and present the conclusion and recommendations.

Submitting project work------It is very important that the project work be submitted and approved according to schedule. Each team member is responsible for submitting, by email, that team member's section on or before the due time and date. Only the team member responsible for a particular section is allowed to submit that team member's work. When work is submitted, there has to be enough time for the work to be reviewed and approved to avoid a late penalty. That is if the work is due by email on a specific date, for example $05 / 16 / 05$, then the work will have to be submitted in time for review and approval. If the work is submitted after $3 \mathrm{pm}$, in the evening on $05 / 16 / 05$, there will not be enough time for the work to be reviewed and approved on $05 / 16 / 05$ and the work will be regarded as late and there will be a grade penalty as detailed below.

Required format for submitting work------The work submitted by email should include all work completed to date on one attached file. As each increment of work is completed, the new increment should be added to the total project work to date on the same one-continuous file and then emailed as an attachment for review and approval. Each section of work should include index tabs for quick reference. This will save substantial time in the review of each section of work.

The schedule for submitting and approval of work is as follows:

A written proposal including the company name, the nature of the company, and a detailed description of each team member's responsibility, exactly in accordance with the syllabus description including the due dates, is to be submitted, using the example matrix form provided, to the professor and approved by email no later than $\mathbf{3 p m}$, 05/16/05. It is also required that a hard copy of the above information together with a copy of the last published balance sheet and income statement for your company be handed in $\mathbf{0 5 / 1 7 / 0 5}$, session III.

Proposals are required to be submitted on the following matrix form.

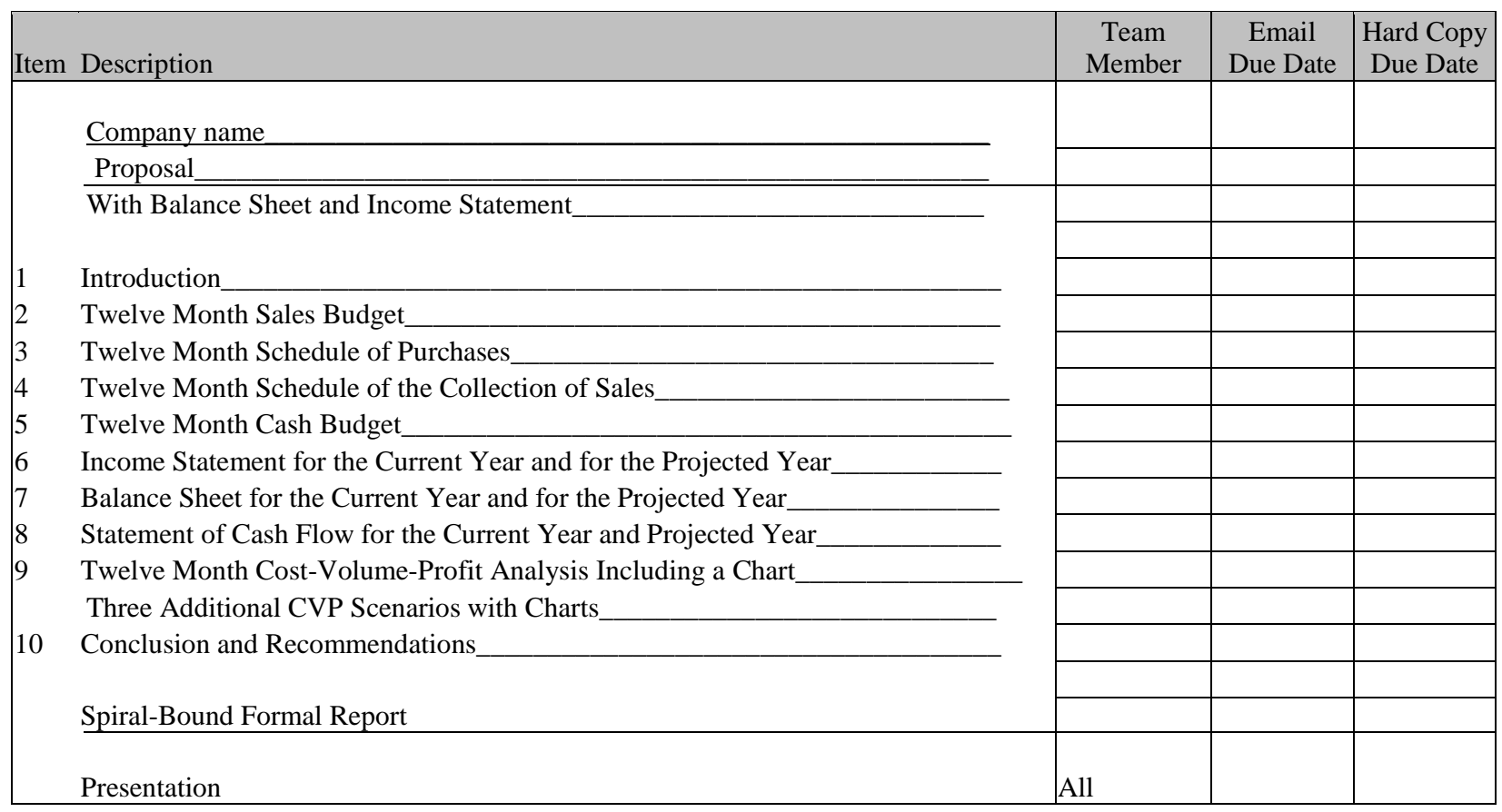


The introduction and history sections will be due at the time of presentation.

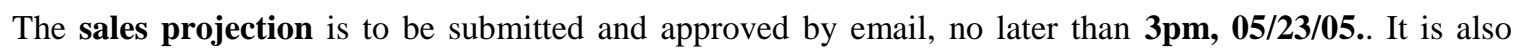
required that a hard copy be handed in $\mathbf{0 5 / 2 4 / 0 5}$, session IV. The same information is also to be submitted to each team member, by email, by session IV.

The projected schedule of purchases and projected schedule of collections are to be submitted and approved, by email, no later than $\mathbf{3 p m , 0 6 / 0 6 / 0 5}$. It is also required that a hard copy be handed in $\mathbf{0 6 / 0 7 / 0 5}$, session VI. The same information is also to be submitted to each team member, by email, by session VI.

The last year's actual and the projected income statements are to be submitted and approved, by email no later than 3pm, 06/20/05. It is also required that a hard copy be handed in $\mathbf{0 6 / 2 1 / 0 5}$, session VIII. The same information is also to be submitted to each team member, by email, by session VIII.

The CVP model, including the contribution margin income statement, the derivation and proof of the reliability of the model and graph for the projected year are to be submitted and approved, by email, no later than $3 \mathbf{p m}, 06 / 27 / 05$. It is also required that a hard copy be handed in $06 / 28 / 05$, session IX.

The projected cash budget is to be submitted and approved, by email, no later than $\mathbf{3 p m , 0 6 / 2 7 / 0 5}$. It is also required that a hard copy be handed in $\mathbf{0 6 / 2 8 / 0 5}$, session IX. The same information is also to be submitted to each team member, by email, by session IX.

The three scenarios for CVP together with the supporting numbers, graphs and analyses are to be submitted and approved, by email, no later than $\mathbf{3 p m , 0 7 / 1 8 / 0 5}$. It is also required that a hard copy be handed in 07/19/05, session XII.

The last year's actual and projected balance sheets and statements of cash flow are to be submitted and approved, by email, no later than $3 \mathbf{p m}, \mathbf{0 7 / 1 8 / 0 5}$. It is also required that hard copies be handed in 07/19/05, session XII. The same information is also to be submitted to each team member, by email, by session XII.

\section{The grading procedure for the project is as follows:}

Grading begins at the beginning in the way that each team moves in the selection of a company and in assigning the duties to each member. (10 points)

The continuous communication, by email, of each team and its members with the professor on the progress being made and the timeliness in which the data is put together and forwarded, by email, to the professor for review and approval. (20 points).

Late work submitted will be penalized 10 points.

Each team member's ability to rework the parts necessary and the timeliness in which the rework takes place. (10 points)

The quality of materials used in making the presentation.

Each members knowledge and understanding of the subject matter being presented and the comprehensiveness of the coverage. The coverage should coincide precisely with the final work submitted.

The quality, correctness and obvious effort of each team member's work submitted in the final paper.

The last three items mentioned above carry 60 points. 
The project is due to be handed in to the professor in one very formal aggregate spirally bound package of the entire project including a table of contents and a description of each team member's work at the beginning of the last class session. Each member on the team will be graded individually. No projects will be accepted past the due date.

The projects will be presented at the last class session. Each team member is required to present the responsible part at the last class session. . Failure of a team member to present that team member's responsible part will result in a loss of $10 \%$ for that team member. Therefore, the maximum possible that could be earned on the project would be $12 \%$. A loss of $10 \%$ is equal to a loss of one full letter grade for the course.

No credit will be given for late projects. Each team is responsible for using presentation materials (power point, overhead slides etc.) that are very legible to everyone. Failure to make a very legible presentation will affect the grade by, at the very least, $15-20$ points out of 100 points. The total possible percentage points on the project is 22.

\section{PROJECT GUIDELINES----NARRATIVE FORM}

The introduction should include a description of the company policies and the plan for the future.

There should be a very thorough coverage on the history of the company. This is certainly one of the most interesting areas in the entire project.

The growth rate should be derived from at least four sources. If available, the growth rate should be relative to revenue; otherwise, earnings per share might have to be used.

The time period covered should begin the day following the last available published annual report. If the most recent annual report is not yet available, then it would be necessary to go back to the last available published annual report and begin the project the day following that annual report.

Sales for the last twelve months will only be available on a quarterly basis; therefore, each quarter will be divided by three in order to get monthly sales.

The growth rate will then be applied to sales for each month which will become the sales forecast for each of the twelve months in the project.

Since inventories are carried at cost and not retail, it is necessary to use the cost of goods sold ratio to convert inventory at retail (the sales value) to inventory at cost by using the cost of goods sold ratio. This ratio is derived from the last actual published income statement in the annual report. The cgs ratio is determined by dividing cost of goods sold by sales in the actual income statement.

The projected schedule of purchases is based primarily on projected sales; however, other factors may enter into the preparation of this schedule. The inventory carried at the end of each month will certainly have to be enough to cover the next month's projected sales. For example, if the next month's sales are projected at $\$ 500,000$, and the cgs ratio is $60 \%$ of the selling price, the ending inventory for this month will have to be at least $\$ 300,000$, which is the cost $(\$ 500,000 \times$. .6) of the next month's sales. The ending inventory plus the cgs for that specific month will be the amount of inventory needed. The needed amount less the beginning inventory will $=$ the amount that has to be purchased. The beginning inventory in the first month of the schedule of purchases is the actual ending inventory from the balance sheet of the last available published annual report.

The projected schedule for the collection of sales is duscretionary based on the policy determined by the team member responsible for this section. For example the policy might be: $50 \%$ of sales collected in the month of sale, $30 \%$ of sales collected one month following the sale and $20 \%$ collected two months following the sale. 
The projected cash budget is a very critical component of any projection. The budget is done on a monthly basis. The beginning cash in the budget is the actual ending cash amount found in the last available published balance sheet. Other sections in the budget include: purchases which is the monthly amount of purchases taken from the projected schedule of purchases; selling, general and administrative expenses taken from the projected income statement and expressed on a monthly basis in the projected cash budget; desired ending cash which is at the discretion of the preparer; cash flows from investing activities which is made up of the purchase and sale of all revenue producing investments such as plant and equipment, land and investments in other companies; cash flows from financing activities which include the purchase and sale of capital stock, issuance and retirement of debt instruments like bonds and notes payable, and the payment of cash dividends. The two sections---- cash flows from investing activities and cash flows from financing activities should correlate directly to these same two sections of the projected statement of cash flow. The difference in the two documents is that the projected cash budget includes these items on a monthly basis whereas the projected statement of cash flow includes these two sections for a twelve month period. . Notes should follow the cash budget describing each item on a line by line basis. The notes should be on the page that follows the cash budget. Each note should have a reference number. The reference number should also be included in the cash budget in a vertical column so that each reference number is on the same line that the reference number pertains to.

The projected income statement should parallel, line by line, the actual income statement of your company. Sales or net revenue is taken from the sales forecast. Cost of goods sold is determined by multiplying the cgs ratio in the projected schedule of purchases by the projected sales. Expenses, such as selling, general and administrative should be based on the same ratio as these expenses relate to sales in the actual income statement of your company. The percentages used in calculating the amounts for the projected income statement should be included, line by line, in a vertical column centered between the last year's income statement and the projected income statement. Use the same income tax rate as that used in the actual income statement of your company. Earnings per share is determined by taking the net income divided by the outstanding number of shares of common stock. Fully diluted shares can be determined by using the relationship of fully diluted eps to primary eps in the actual income statement of your company and applying that relationship to the projected income statement.

The balance sheet should parallel, line by line, the actual balance sheet of your company. Cash will be taken from the ending cash in the projected cash budget. Accounts receivable will be the ending balance of accounts receivable taken from the projected schedule for the collection of sales. Inventory will be the ending inventory taken from the projected schedule of purchases. Plant and equipment should be the previous year's balance plus new acquisitions. Your team will determine if your projection includes plans to buy new plant and equipment. Accounts payable will be the ending balance taken from the projected schedule of purchases, depending upon the payment policy for the purchase of inventory. For example, if purchases of inventory are paid for in the month immediately following the purchase, then the amount purchased in the last month of the projection will be the outstanding balance for accounts payable. Notes payble will be the last year's balance plus new notes less amounts paid during the year on existing notes. Bonds payable will be the last year's balance plus new issuances of bonds less amounts paid during the year on existing bonds. Common stock will be the last year's balance plus new issuances less any stock purchased or retired. Retained earnings will be the last year's balance plus net income on the projected income statement less dividends declared during the year. There will be certain items on your company's last year's balance sheet that you will not be able to identify or calculate, such as deferred taxes. Because of the unidentifiable nature of these items they should be brought over to the projected balance sheet either in the same amount or in an amount needed to balance the document. Notes should follow the balance sheet describing each item on a line by line basis. The notes should be on the page that follows the balance sheet. Each note should have a reference number. The reference number should also be included in the balance sheet in a vertical column so that each reference number is on the same line that the reference number pertains to.

The statement of cash flow operating activities section should parallel, line by line, the actual statement of cash flow of your company. You will be using the method that we cover in class in determining the amounts in the operating activities section. There may also be items in this section that cannot be identified or calculated. Because of the unidentifiable nature of these items, they should be brought over to the projected statement of cash flow either in the same amount or in amount needed to balance the document. The investing activities section will include new 
cash acquisitions of plant and equipment or other investments and the cash amounts sold during the year. This section should correlate directly to the investing activities section of the projected cash budget, on an annual basis rather than a monthly basis. The financing activities section will include new cash issuances of debt and capital stock. This section will also include retirement for cash of old issuances of debt and capital stock and payments of cash dividends. This section should correlate directly to the financing activities section of the projected cash budget, on an annual basis rather than a monthly basis. Notes should follow the statement of cash flow describing each item on a line by line basis. The notes should be on the page that follows the statement of cash flow. Each note should have a reference number. The reference number should also be included in the statement of cash flow in a vertical column so that each reference number is on the same line that the reference number pertains to.

The cost-volume-profit analysis section begins with the derivation and explanation of the model. The model is expressed in the contribution margin format. The central part of the model is the variable cost ratio to sales. For example, if the vc ratio to sales is $80 \%$ or .8 , then for every dollar of sales, there will be a variable cost of 80 cents. This ratio has to be determined before any part of cvp analysis can take place.

The most effective approach in deriving the vc ratio is through the use of the high-low method. The extent of the calculation will depend upon whether the company being examined is a merchandising company or a manufacturing company.

The following pertains to a merchandising company.

For a merchandising company, the vc ratio to sales is in two parts, the cost of goods sold vc ratio and the selling general and administrative vc ratio. The first part, cost of goods sold, is a purely variable cost, and the variable cost ratio for cgs is determined by dividing cgs by sales in either the actual or the projected income statement. The use of the high-low method is not necessary.

The second part, sg\&a, is more involved because the sg\&a expenses are mixed expenses. Mixed expenses contain both variable and fixed components. In order to complete the variable cost ratio, the variable and fixed components have to be disaggregated. This is accomplished through the use of the high-low model.

To determine the vc ratio for sg\&a, the high-low model is applied to the last two year's actual income statements, such as the years 2001 and 2000, as follows:

1. Sg\&a for the year 2000 is subtracted from sg\&a for the year 2001.

2. Sales for the year 2000 is subtracted from sales for the year 2001.

3. By dividing the answer in 1. above by the answer in 2. above, the variable cost ratio to sales for sg\&a is determined.

Alternatively expressed as follows:

$\underline{2001 \mathrm{sg} \& \mathrm{a}-2000 \mathrm{sg} \& \mathrm{a}}=$ the variable cost ratio for sg\&a to the sales dollar

2001 sales -2000 sale

The following pertains to a manufacturing company.

For a manufacturing company, the variable cost ratio is also in two parts, the variable cost of goods sold ratio to sales and the $\operatorname{sg} \& a$ variable cost ratio to sales. The difference in the manufacturing company and the merchandising company is that the manufacturing company cgs contains both a variable and a fixed component, while the merchandising company cgs is a purely variable cost. Therefore, the high-low method is used to determine the vc ratio of cgs to sales and also to determine the vc ratio of sg\&a expenses to sales. 
To determine the vc ratio for cgs, the high-low model is applied to the last two year's actual income statements, such as the years 2001 and 2000, as follows:

1. $\quad$ Cgs for the year 2000 is subtracted from cgs for the year 2001.

2. $\quad$ Sales for the year 2000 is subtracted from sales for the year 2001.

3. By dividing the answer in 1 . above by the answer in 2. above, the variable cost ratio for cgs is determined.

Alternatively expressed as follows:

$2001 \mathrm{cgs}-2000 \mathrm{cgs}=$ the variable cost ratio for cgs to the sales dollar 2001 sales -2000 sales

To determine the vc ratio for sg\&a, the high-low model is applied to the last two year's actual income statements, such as the years 2001 and 2000, as follows:

1. Sg\&a for the year 2000 is subtracted from sg\&a for the year 2001 .

2. $\quad$ Sales for the year 2000 is subtracted from sales for the year 2001.

3. By dividing the answer in 1 . above by the answer in 2. above, the variable cost ratio to sales for sg\&a is determined.

Alternatively expressed as follows:

$2001 \mathrm{sg} \& \mathrm{a}-2000 \mathrm{sg} \& \mathrm{a}=$ the variable cost ratio for sg\&a to the sales dollar

2001 sales -2000 sales

The following pertains to both merchandising and manufacturing companies:

Once the two vc ratios to sales have been determined for cgs and $\operatorname{sg} \& a$, the two ratios are taken to the contribution model income statement and included in the variable cost section.

The fixed component of any mixed expense or cost is a residual of the remaining expense or cost after subtracting out the variable component from the total expense or cost.

For example: Suppose that

1. Total sg\&a expense is $\$ 1,200,000$.

2. Total sales is $\$ 3,000,000$.

3. The variable cost ratio to sales is $15 \%$ or .15 .

4. The variable component of total sg\&a is $\$ 450,000(\$ 3,000,000 \times .15)$.

5. The fixed component of total sg\&a is $\$ 750,000(\$ 1,200,000-\$ 450,000)$.

The same approach would be applied to total cgs in determining the fixed component of cgs.

The fixed component of any expense is never expressed as a percentage of the sales dollar. Fixed expenses may be expressed as a percentage of a total expense, but never as a percentage of the sales dollar. To express fixed expenses as a percentage of sales implies that fixed expenses are directly correlated to the sales dollar. This is incorrect. As total sales increase over time, the company will probably be expanding and total fixed expenses would increase as a result; however, the increase in fixed expenses would not increase directly with the sales dollar.

After the fixed components have been determined, they are also taken to the contribution model income statement together with the variable cost ratios. 
The basic contribution model appears as follows:

\begin{tabular}{|c|c|c|}
\hline Sales & $\operatorname{xxxxxxxx}$ & \\
\hline -Variable cost & $\operatorname{xxxxxxx}$ & .8 (variable cost ratios for both cgs and sg\&a) \\
\hline $\begin{array}{l}\text { Contribution margin } \\
\text { - Fixed costs }\end{array}$ & $\begin{array}{l}\mathrm{Xxxxx} \\
\mathrm{xxx}\end{array}$ & 2 (Contribution margin ratio) \\
\hline Net income & & \\
\hline
\end{tabular}

The next section pertains to proving the reliability of the model. The reliability of the model is established when the income from operations(does not include interest or taxes), based on the contribution margin model, is the same as the income from operations ( does not include interest or taxes) in the projected income statement. Income from operations includes revenue less cost of goods sold and expenses from operations. Interest and taxes are not included in this number.

This is proven as follows:

1. Calculate breakeven in sales dollars by dividing total fixed costs by the contribution margin ratio (.2 in the example above).

2. Subtract breakeven sales dollars from total projected sales dollars in the projected income statement. The difference in sales dollars is defined as the profit region in sales dollars.

3. The profit region in sales dollars multiplied times the contribution margin ratio, (.2 in the example above) equals net income before tax in the contribution margin model.

4. In order for the contribution model to be proven as reliable, the income from operations in the contribution margin model has to equal the income from operations in the projected income statement.

\section{PROJECT GUIDELINES-------ABBREVIATED FORM}

1. Introduction should include the following:

History of the company

Policies of the company

2. Sales forecast for twelve months

Calculated by applying the growth rate (acquired from analysts) to each of the past twelve months of actual data which then becomes projected sales.

3. Schedule of purchases for twelve months

Calculated by determining the amount of inventory on hand needed for your company and applying the cost of goods sold ratio (from the actual income statement) to the needed inventory so that the inventory is included in the schedule at cost. The policy on the amount of inventory to be carried is the team member's choice.

4. Schedule for the collection of sales. The policy for collections is the team member's choice.

5. Cash budget should include the following:

Beginning cash from the actual balance sheet included in the last year's annual report.

This beginning cash figure is the actual ending cash figure from the actual balance sheet.

Cash collected from sales from the schedule for the collection of sales.

Cash expenses which should also tie in to the projected income statement. 
All items in the investing and financing activities the sections of the projected statement of cash flow. Investments of excess cash into short term marketable securities. Interest earned on the short term investments as additional cash.

6. Income statement format should be reasonably consistent with the company's past year income statement and should include the following:

Sales from the sales forecast.

Expenses relatively consistent with the expenses on the past year income statement.

Relate the expenses to sales.

Interest earned from investments in short term securities from the cash budget (other income)

Tax rates should be consistent with the last year's income statement.

7. Balance sheet should include the following:

Cash is taken from the ending cash in the cash budget.

Accounts receivable will be what has not been collected at the end of the year. This should come from the person preparing the schedule of collections.

Inventory will come from the schedule of purchases.

Other assets should be taken from the previous year's balance sheet with an adjustment for growth.

Plant assets should be consistent with the previous year's balance sheet with changes made consistent with the investing activities section of the statement of cash flow.

Long term debt should be consistent with the previous year's balance with changes made for any payment on the debt plus any additions that will come from the statement of cash flow in the financing activities section.

8. Statement of cash flow should include the following:

Cash flow from operating activities which include:

Net income from the income statement.

Depreciation, amortization, depletion, gains and losses from the income statement.

Changes in current assets and liabilities taken from the actual balance sheet and the projected balance sheet.

Cash flow from investing activities which include:

Purchases of new plant and equipment according to growth in the company also included in the cash budget.

Sales of plant and equipment, also included in the cash budget.

Cash flow from financing activities which include:

Issuances of capital stock for cash, also included in the cash budget.

Purchases of treasury stock for cash, also included in the cash budget.

Issuances of long term debt for cash, also included in the cash budget.

Retirement of long term debt for cash, also included in the cash budget.

Payments of cash dividends, also included in the cash budget.

The net increase or decrease in cash should check with difference in the beginning and ending cash in the actual (last year's) and projected balance sheet.

9. Cost volume profit analysis.

This section begins with determining the variable cost ratio to sales. 
For a merchandising concern, this would be the cost of goods sold ratio to sales plus the ratio of variable operating expenses as they relate to sales.

For a manufacturing concern, this would be the variable part of cost of goods sold as it relates to sales (the ratio) plus the ratio of variable operating expenses as they relate to sales.

The contribution margin ratio and break even dollar sales have to be consistent with the projected income statement net income. That is, the difference in break even dollar sales and total dollar sales in the projected income statement multiplied times the contribution margin ratio has to equal the income from operations in the projected income statement. If this does not match, then the ratio has to be reworked until there is a match.

Companies not allowed for projects this term:

Amge, Unis, Home Depot, EMC, Nike, Barnes \& Noble, Broadcom, Best Buy, Guitar Center, Sears, Pfizer, Right Start, Coca C, Microsoft, Blockbuster, Border's, Vans, Caterpillar, Merk, Ann Taylor, Ethan Allen, Diedrich Coffee, Colgate Palmolive, Fossil, Mentor, Polo Ralph Lauren, Rawlings, William Sonoma, Abercrombie \& Fitch, GMC, Kodak, Harley Davidson, Staples, Federated Dept. Stores, Starbuck's, Chalone, Avery Dennison, Gymboree, SureB, Allergan, Costco, Coach, Whole F, Peet's Coffee \& Tea, Johnson \& Johnson, Electronic Art, Starbuck's, Maytag, Avid Tech, Jakks Pacific, Intel, Activision, K2, Gap, Texas Instruments, McDonald's, Quiksilver, Apple, Genetech, AMD, IGT, Fortune Brands, Boston Beer, Sketchers, Variflex, Pepsico, Amerisource Bergen, 3M, Abbot Labs, Auto Nation, Martha Stewart, Brookstone, Vulcan Materials, Sharper Image, Th Q, H-P, DuPont, St Jude Medic, Columbia Sportswear, Pep Boys, Grainger, John Deer, TIVO, Zale's, Friendly Ice Cream, Inamed, Shering Plough, Sherwin Williams, Liz Claiborn, Office Depot, Timberland, Yankee Candle, Applebee's, Albertson's, Bausch \& Lomb, Circuit City, Kimberly Clark, Lokheed Martin, Target, Biogen, Eli Lily, Farmer Bros., Franklyn Covey, Medtronic, Paul-Son Gaming, Snap-On Tools, Boston Acoustics, Deckers Outdoors Corp, KB Homes, NCR, Outback Steakhouse Inc., Schulman's, JC Penney, Krispy Kreme, Movado, Boston Scientific, Cisco, Gillette, IBM, Callaway, Goodyear, Guess, Lexmark, Nordstrom's, Radio Shack, Walgreen's, 